\title{
FIRE-INDUCED RE-RADIATION UNDERNEATH PHOTOVOLTAIC ARRAYS ON FLAT ROOFS
}

\author{
J. Steemann Kristensen ${ }^{1,3}$, B. Merci ${ }^{2}$ \& G. Jomaas ${ }^{1,3}$ \\ ${ }^{1}$ Deptartment of Civil Engineering, Technical University of Denmark, 2800 Kgs. Lyngby, Denmark. \\ ${ }^{2}$ Deptartment of Flow, Heat and Combustion Mechanics, Ghent University 9000 Ghent, Belgium. \\ ${ }^{3}$ BRE Centre for Fire Safety Engineering, School of Engineering, University of Edinburgh, Edinburgh \\ EH9 3JL, UK.
}

\begin{abstract}
The impact of the reflection of fire-induced heat from a gas burner was studied experimentally to gain knowledge on the interaction between photovoltaic (PV) panels and a fire on flat roofs. The heat flux was measured in a total of eight points at the same level as the top of the gas burner. The gas burner was placed underneath the centre of a PV panel, installed in a geometry similar to a commercial EastWest orientated mounting system, and the eight points were symmetrical pairs of two at four different distances from the burner. Measurements were compared to tests with no PV panel, and thereby without the reflection from the PV panel. A significant increase of the received heat flux was recorded, with ascending percentage-wise difference for increased heat release rates. This indicates that PV panels can have a significant contribution in roof fires, primarily because they stimulate fire spread over the roof on which they have been mounted. The received heat flux is higher underneath the most elevated part of the PV panel, due to two important, flame-related reasons: 1) the flame deflection towards the most elevated part of the panel; 2) a non-homogeneous temperature distribution on the PV panel surface, due to the deflected flame, and thereby a non-homogeneous emission from the heated PV panel. Finally, the results were very similar for a brand new PV panel and a PV panel tested for the fourth time, except during the period when the thin combustible film underneath the new PV panel is burning, supporting that it is the fire dynamics and not the fire load associated with the PV panels that is promoting fire spread associated with PV panels on flat roofs. With this in mind, the current results are not only relevant for PV panels, but also for any inclined roof covering panel with limited combustibility.
\end{abstract}

\section{INTRODUCTION}

Over the last decade, the amount of energy produced by photovoltaic installations has grown rapidly from $5.7 \mathrm{GW}$ in 2006 [1] to $303 \mathrm{GW}$ in 2016 [2]. The economic gains of PV installations versus conventional energy based on fossil fuels is an ongoing discussion, which we do not have the knowledge to participate in. In some parts of the world the increase is stimulated by beneficial state funding, while also companies invest in photovoltaic energy (e.g., companies like Walmart, Target, Apple and IKEA are among the top 10 solar capacity companies (90\% roof mounted) in the US with maximum potentials between $41-142 \mathrm{MW}$ [3]). This indicates environmental as well as economic stimuli for increased use of PV installations.

However, the installation of PV arrays introduces new and not yet well-studied fire related risks to the roof construction, which is of great interest for all parties involved in PV related power, from the manufacturer of the panels to the owner of the facilities and their insurance companies, and local authorities including fire fighters. In a risk assessment of the Italian national fire services guidelines, Cancelliere [4] divides current the fire related studies of PV panels into three main categories: (1) ignition, (2) propagation of the fire, and (3) the safety of personnel, including fire fighters.

The installation of large PV arrays, and thereby large power generating DC systems, introduces a risk of electronic malfunctions and thus a possibility of ignition and fire. Wohlgemuth and Kurtz [5] divided the causes of fire hazards into three categories: (1) hot spots, (2) high series resistance and (3) arching. Pandian et al. [6] studied the consequence of shading faults on PV panels and concluded that the 
temperature of the PV panel is a potential hazard, especially in the hydrocarbon industry. Solar America Board for Codes and Standards (Solar ABCs) and UL studied the Bakersfield fire [7] and suggested that a current of 1000 ampere in a small, unprotected $10 \mathrm{AWG}$ wire was the source of ignition. In general, it seems to be well accepted to assume an electric malfunction to be the main cause of PV related fires, which is why the field is well studied by the electronics industry (e.g., Zhao et al. [8] who made a fault analysis of PV arrays to avoid safety hazards).

Each element added to a roof construction can be seen as an addition to the fire load. A PV panel's reaction to flames is tested in the European standard IEC 61730-2:2016 [9] and the American equivalent UL 1703 [10]. Despinasse and Krueger [11] found that the current tests are based on test methods that are not easily reproduced, and are therefore working on developing a method where the PV panel's reaction to a propane flame is tested. Even though parts of a PV panel are combustible, the current authors have earlier concluded that the PV panel, as a fuel load, does not represent a large fire hazard for a roof construction [12]. Figure 1 shows the heat of combustion as measured by bomb calorimetry for the components of two PV panels from different producers. Despite the high heat of combustion values found for the parts that were tested, the combined mass of the combustible components represents less than $1 \%$ of the panels' total mass (approximately $20 \mathrm{~kg}$ ) and the overall fuel load is therefore limited.
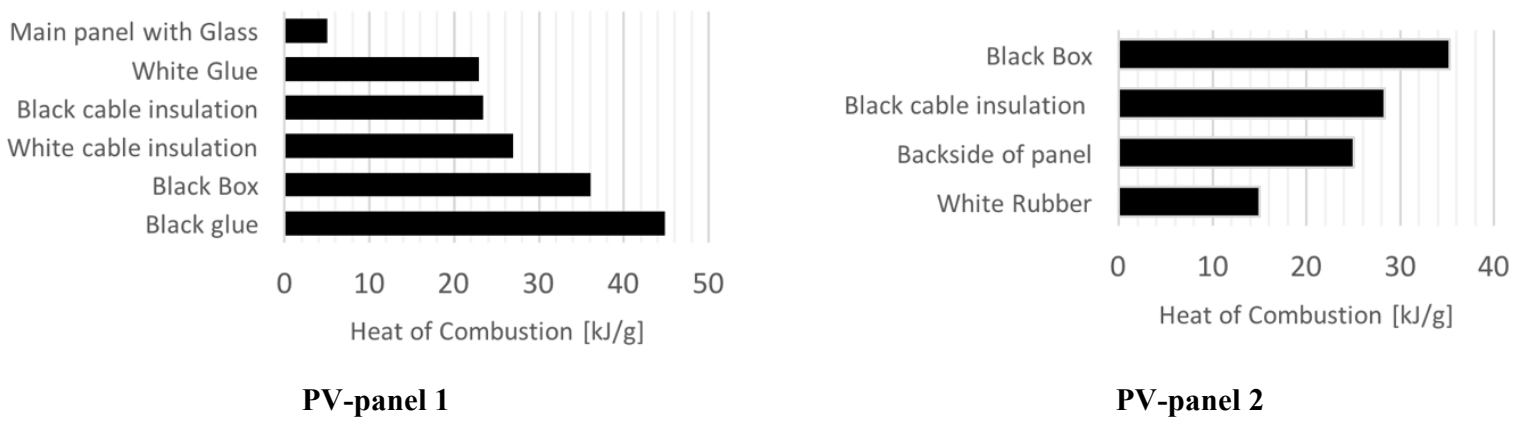

Figure 1. Heat of Combustion of the combustible components of two PV-panels. The term Black Box is used for the combining box on the backside of the panels.

The safety for fire fighters has been addressed by SFPE [13], UL [14] and The Fire Protection Research Foundation [15]. The risk of being electrocuted during fire extinguishment actions has furthermore been studied by Tommasini et al. [16], who concluded that panels with a voltage up to $1000 \mathrm{~V}$ DC could be extinguished safely, by respecting normal safety distances. Lastly, the Solar ABCs have concluded that the installation of PV panels on sloped roof constructions reduced the fire related properties of the subjacent material [17].

Due to limited registration, it has not been possible to obtain an exact number or estimate of fires that occur worldwide due to the installation of PV arrays. However, data from incident reports produced by the Italian National Fire Corp. [18] reveal that the number of PV related fires in Italy has increased significantly since 2009. With less than two annual PV related fires between 2003 and 2006, a maximum of 30 annual fires until 2009, and an exponential increase to 800 fires in 2012 [19], it is clear that the rapid increase in the number of PV installations also has resulted in fire related issues. In 2014, the amount of fires dropped to 469 [19], most likely due to the introduction of regulations and a better workforce [18].

Based on the approach that the PV panels do not contribute with a significant fire load to the roof construction, it is of interest to study why large fires involving PV installations are occurring on regular basis. Well aware that the fires occur, and accepting that the fire load of the PV panel is limited, it is assumed that the installation of PV arrays changes the fire conditions by reflecting a significant fraction of the heat, which under normal circumstances would be released into the open air, back towards the 
surface of the roof construction.

The matter of a possible propagation of fire, without regard to the actual source of the fire, strongly depends on how the surrounding environment responds to the ignition, which once again depends on the critical heat flux for ignition of the adjacent materials. Any reflected heat would be added to the heat flux from the fire, resulting in a increased total heat flux towards the top of the roof construction, and when or if the total heat flux exceeds the critical heat flux for the subjacent material, it will ignite. Thus, the propagation of a fire beyond the point of ignition, say from a faulty wire, basically depends on the ratio between the critical heat flux of the unignited material versus the heat flux received from the surroundings. The hypothesis herein is therefore that a propagation of a fire can only occur in a roofing membrane if the membrane's critical heat flux is exceeded by the sum of the heat from the ignition source or burning roofing membrane and the heat reflected by the PV panels.

The main aim of the experiments presented herein is therefore to examine how the installation of a PV panel influences the energy release from a realistic flaming fire source, which was represented by a gas burner. The gas burner made it possible to define different steady state heat release rates (HRR), and these well-controlled HRRs enabled the possibility of a comparison between the heat flux received at the same spot, with and without the reflection from the PV panel.

\section{THEORY}

Like any other fire, a fire on a roof construction would influence the surroundings with the three types of heat transfer: conduction, convection and radiation. If there is a PV installation above the fire on the roof construction, a large fraction of the fire-induced radiation will either be absorbed by the panel or reflected back towards the surface of the roof construction that is located underneath the panel. The absorbed heat, together with the heat received from convection, will increase the temperature of the panel resulting in an enhanced amount of emission from the panel according to the Stefan-Boltzmann law.

Based on the view factor theory and an assumption of a homogenously distributed temperature over the entire PV panel surface, it is possible to calculate the radiative heat transfer between the solid surface $A C$ and the point $D$ in Figure 2. The view factor in point $D$, as a function of the $\mathrm{x}$-axis distance between point $B$ ( 0 on the x-axis) and $D$ can be seen in Figure 3 and Figure 4 for respectively different angles, $\theta$, and elevations, $h_{E}$, of the solid. The graphs indicate that the received heat flux by radiation emission from the heated panel decreases as a function of an increased elevation or a decreased angle. It is furthermore noticed that the view factor is largest underneath the least elevated part of an inclined panel, as expected.

In the case of an angled PV installation, a convectional contribution of heat from the flow of hot air underneath the installation is expected, possibly combined with radiation from the smoke and the flame. Herein, the different heat sources are not treated separately, because it is the combined additional heat that represents the increased hazard to the subjacent surface, and the main objective is to examine whether or not the additional contribution of heat is significant for the propagation of a possible fire. 


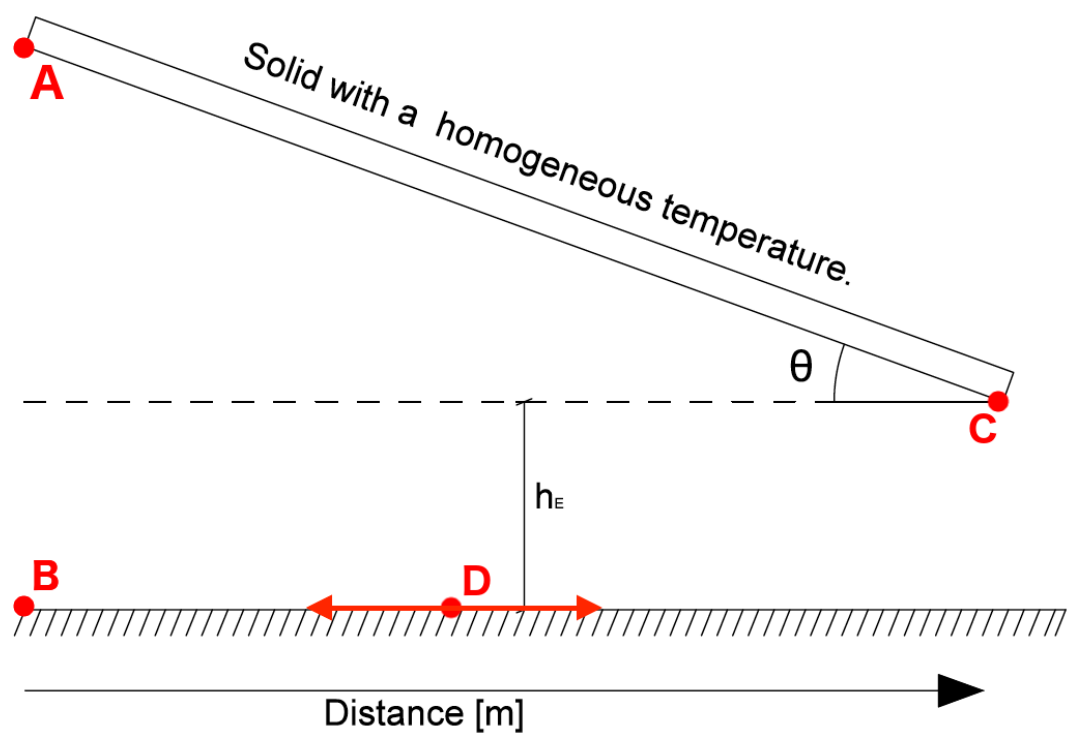

Figure 2. Simplified set-up of a solid with the angle $\theta$ and the elevation $h_{E}$ above a surface.

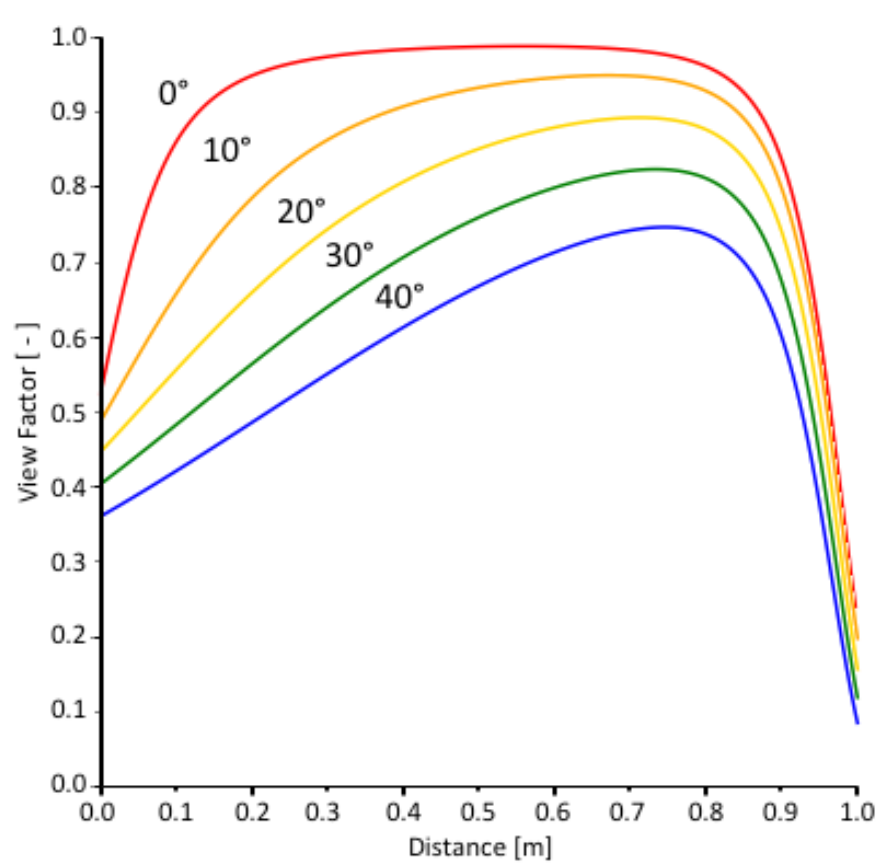

Figure 3. Theoretical view factor as a function of the $\mathrm{x}$-axis distance between point $\mathrm{B}$ ( 0 on the $\mathrm{x}$-axis) and $\mathrm{D}$, the angle $\theta$ and a fixed elevation of $\mathrm{h}_{\mathrm{E}}=0.1 \mathrm{~m}$ in Figure 2. 


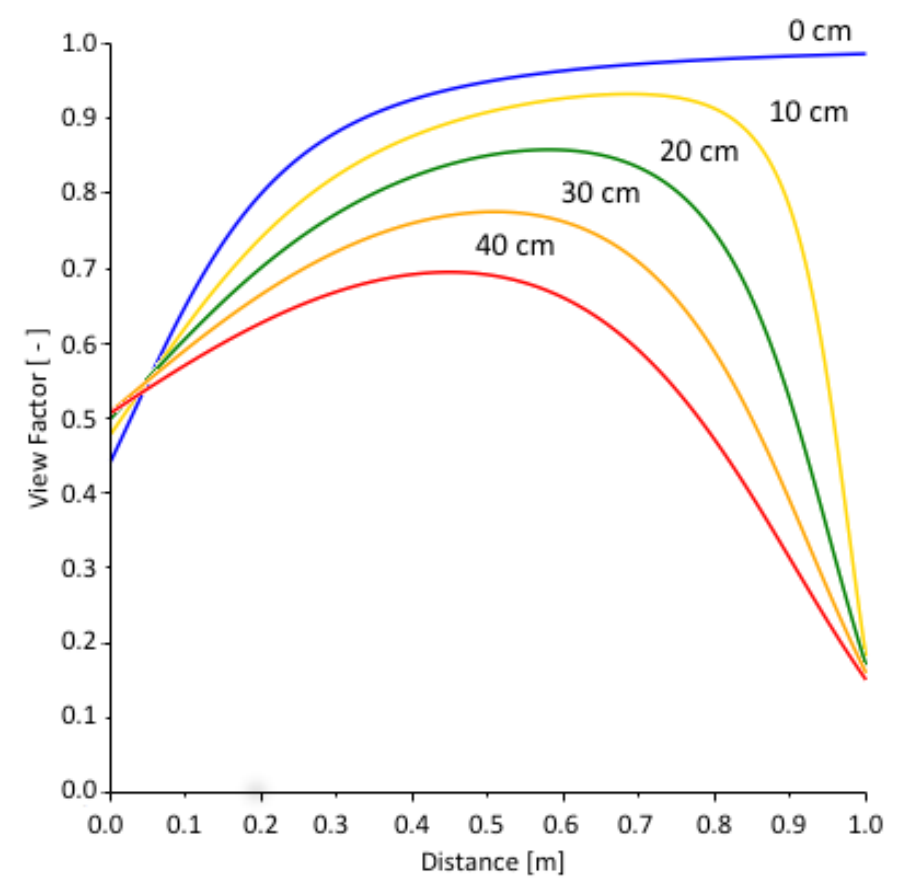

Figure 4. Theoretical view factor as a function of the $\mathrm{x}$-axis distance between point $\mathrm{B}(0$ on the $\mathrm{x}$ axis) and $D$, the elevation $h_{E}$ and a fixed angle of $\theta=10^{\circ}$ in Figure 2.

\section{SETUP, APPROACH AND LIMITATIONS OF THE EXPERIMENT}

\subsection{Setup}

The setup seen in Figure 5 was constructed with a Bosch Rexroth modular system, which made it possible to change the elevation and angle of the tested PV panel by adjusting $h_{L}$ and $h_{R}$. Two PV panels with dimensions of $1.0 \mathrm{~m} \times 1.7 \mathrm{~m}$ were tested. The panels were poly-crystalline panels designed with a front layer of glass and polymer back sheet encasing the PV cells. The main panel was stabilized by a $40 \mathrm{~mm}$ aluminum frame and the panel could be connected to a PV system via two connection cables. Because the objective was to test the PV panel's influence on the heat flux received at the subjacent surface it was decided to cut both connection cables and thereby avoid an additional, but nonreproducible, fire load from the panels. The junction boxes were not removed as they were glued to the panel, but since the junction boxes were installed along one of the short edges of the panel, and the tests were conducted at the centre of the $1.7 \mathrm{~m}$ long edge, they were not ignited or involved in the tests at any moment. 


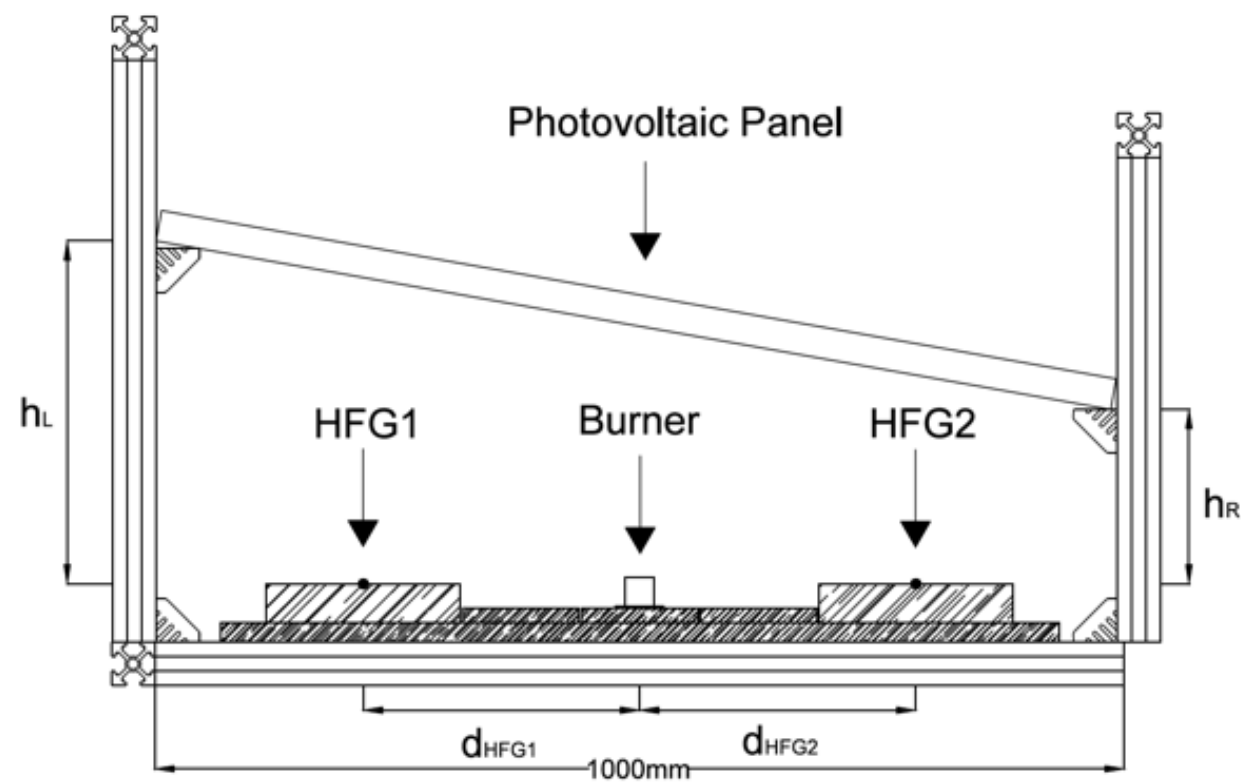

Figure 5. Schematic of the setup used to study the reflection. The hatched areas underneath the Burner and the Heat Flux Gauges (HFG) are made up of non-combustible insulation.

A scaled sandbox gas burner was placed in the center of the setup, using liquefied petroleum gas (LPG) with minimum $90 \%$ propane and maximum $10 \%$ butane as fuel. Due to uncertainty with respect to the exact composition of LPG, the HRR has been calculated using the heat of combustion $\left(\Delta H_{C}\right)$ for propane. It is noted that the error is small, given the very similar $\Delta H_{C}$ values for propane and butane (respectively $46.3 \mathrm{MJ} \mathrm{kg}^{-1}$ [20] and $45.7 \mathrm{MJ} \mathrm{kg}^{-1}$ [20]). The gas flow was controlled by a Bronkhorst flow meter with a maximum flow rate of $10 \mathrm{l} / \mathrm{s}$ and thereby thus a maximum HRR of $14 \mathrm{~kW}$ from the burner. Due to the sensitivity of the used Heat Flux Gauges (HFGs), the maximum HRRs were not used.

The HFGs were water cooled Hukseflux SBG01 thermal sensors with a working range around $5 \mathrm{~kW} / \mathrm{m}^{2}$. As seen from Figure 5, the HFGs were installed in a $40 \mathrm{~mm}$ thick board of non-combustible insulation to avoid unintended heating from the sides. The insulation boards with the HFGs could be moved horizontally on top of the subjacent second layer of non-combustible insulation - making it possible to measure the heat flux in different positions for each test. The sensor of each of the HFGs were furthermore elevated to the same height as the top of the burner to avoid shadowing effects. Both the water supply to the HFGs and the gas supply to the burner were placed underneath the insulation to prevent influence from the heat.

\subsection{Test matrix}

An overview of the conducted tests is shown in Table 1, where the nine tests have been divided into three subgroups: A) test with No PV panel (NP), B) a test series similar to A, but with an inclined PV panel installed above the gas burner as seen in Fig. 5, and C) a test similar test 2.4 with a new PV panel. The difference between the results in NP and WP was used to examine the difference between the heat flux received at the same distances from the gas burner, with and without the influence of the PV panel. In test series WP the panel was placed in a geometry similar to the mounting system used for an EastWest orientated panels.

An overview of the conducted tests is shown in Table 1, where the nine tests have been divided into three subgroups. The difference between the results in test NP and WP was used to examine the difference between the heat flux received at the same distances from the gas burner, with and without 
the influence of the PV panel. In test WP the panel was placed in a geometry similar to the mounting system used for an East-West orientated panels.

Table 1. Schematic overview of the experiments conducted. All dimensions are in $\mathrm{cm}$.

A) NP - No PV Panel

\begin{tabular}{ccccc}
\hline Test \# & $\mathrm{h}_{\mathrm{L}}$ & $\mathrm{h}_{\mathrm{R}}$ & $\mathrm{d}_{\mathrm{HFG} 1}$ & $\mathrm{~d}_{\mathrm{HFG} 2}$ \\
\hline 1.1 & - & - & -28.5 & 28.5 \\
1.2 & - & - & -22 & 22 \\
1.3 & - & - & -16 & 16 \\
1.4 & - & - & -11 & 11 \\
\hline
\end{tabular}

B) WP - With PV Panel

\begin{tabular}{ccccc}
\hline Test \# & $\mathrm{h}_{\mathrm{L}}$ & $\mathrm{h}_{\mathrm{R}}$ & $\mathrm{d}_{\mathrm{HFG} 1}$ & $\mathrm{~d}_{\mathrm{HFG} 2}$ \\
\hline 2.1 & 32 & 9 & -28.5 & 28.5 \\
2.2 & 32 & 9 & -22 & 22 \\
2.3 & 32 & 9 & -16 & 16 \\
2.4 & 32 & 9 & -11 & 11 \\
\hline
\end{tabular}

C) Similar to test 2.4 - with new PV

\begin{tabular}{ccccc}
\hline Test \# & $\mathrm{h}_{\mathrm{L}}$ & $\mathrm{h}_{\mathrm{R}}$ & $\mathrm{d}_{\mathrm{HFG} 1}$ & $\mathrm{~d}_{\mathrm{HFG} 2}$ \\
\hline 3.1 & 32 & 9 & -11 & 11 \\
\hline
\end{tabular}

\subsection{Approach}

Each test was made with an increase of the HRR by $1 \mathrm{~kW}$ for approximately 4 minutes each - a slight difference of the time intervals occurred because it was a manual process. All of the tests were running with $0 \mathrm{~kW}$ for an initial start-up period to ensure the heat flux received from the surroundings was constant. The PV panels were kept at room temperature for at least 40 minutes between each test to avoid the heat from a previous test to influence the following test. Because of the sensitivity of the used HFGs and because only two new PV panels were available for the tests, it was decided to stop the tests if the received heat flux underneath the PV panels exceeded $7.5 \mathrm{~kW}$ for a continuous period. The decision was primarily made to protect the HFGs but also to avoid structural damage of the panels, including broken glass, which could influence the results.

\subsection{Limitations of the experiment}

The experiments were conducted under conditions where the amount of unknown parameters were limited to a minimum, which made it possible to study the influence of the PV panel. The study did not include different wind conditions or the influence of burning droplets, which may be interesting extensions of the experiment when a full understanding of the heat transfer is obtained. The limitations made it possible to understand a key parameter related to the spread of fire.

\section{RESULTS AND DISCUSSION}

\subsection{Influence of the PV panel}

The actual experimental setup can be seen in Figure 6. It is important to notice the deflection of the flame towards the most elevated part of the PV panel. The consequence of the deflected flame can be seen in Figure 7 where the received heat flux is plotted as a function of time, and therefore on the HRR from the gas burner.

In Figure 7, it is seen that the highest heat flux is measured by HFG1, positioned underneath the most elevated part of the panel (see Fig. 6), which means that the view factor theory alone (Fig. 3 and Fig. 4) cannot explain the results. Furthermore, Fig. 7 shows that the increase in HRR from the gas burner 
results in an increase of the received heat flux on the subjacent surface. In addition, the fluctuations increase for increased HRR, and these fluctuations in the measured heat fluxes probably relate to fluctuations of the flame length from the gas burner. From the last period in the measurements (Figure 7) it is seen that the emission from the PV panel, due to its increased temperature, is limited to approximately $2 \mathrm{~kW} / \mathrm{m}^{2}$ immediately after interruption of the gas flow (and thereby the almost immediate disappearing of the flame). As the panel cooled down, the measured radiation emission descends towards it original state of approximately $0 \mathrm{~kW} / \mathrm{m}^{2}$.

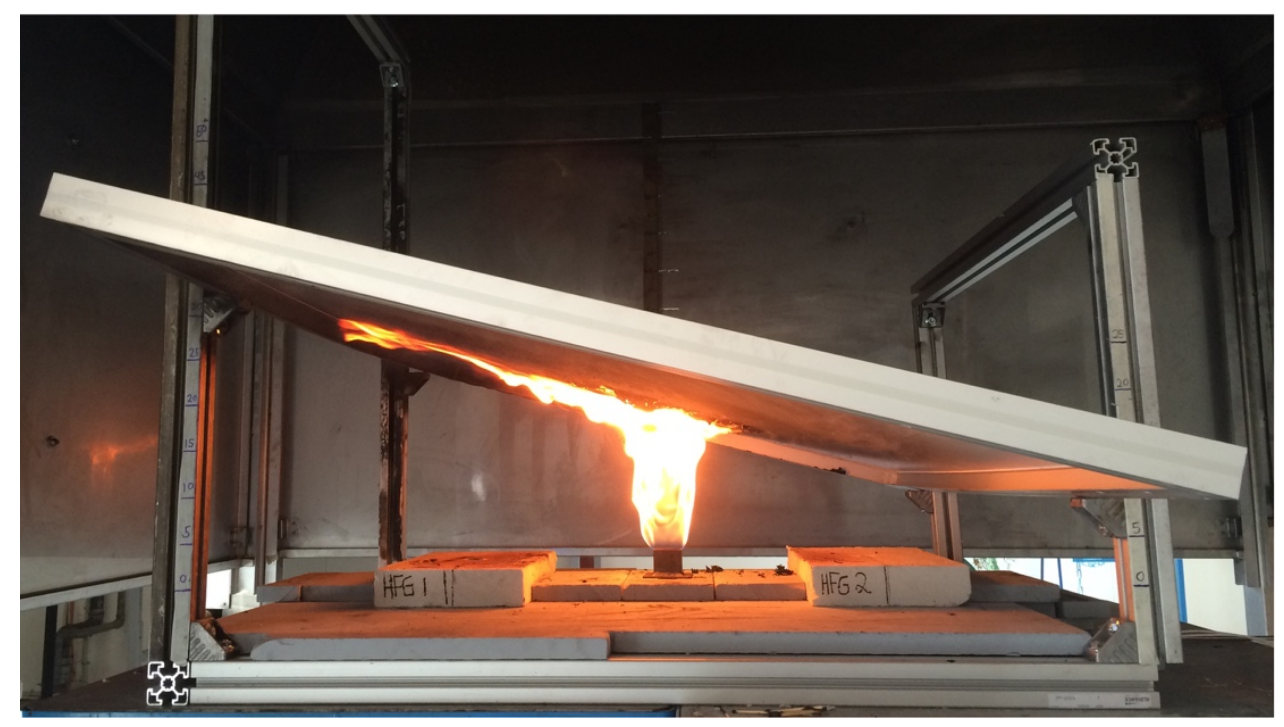

Figure 6. Photo of the setup showing that the flame is deflected significantly upwards underneath the PV panel.

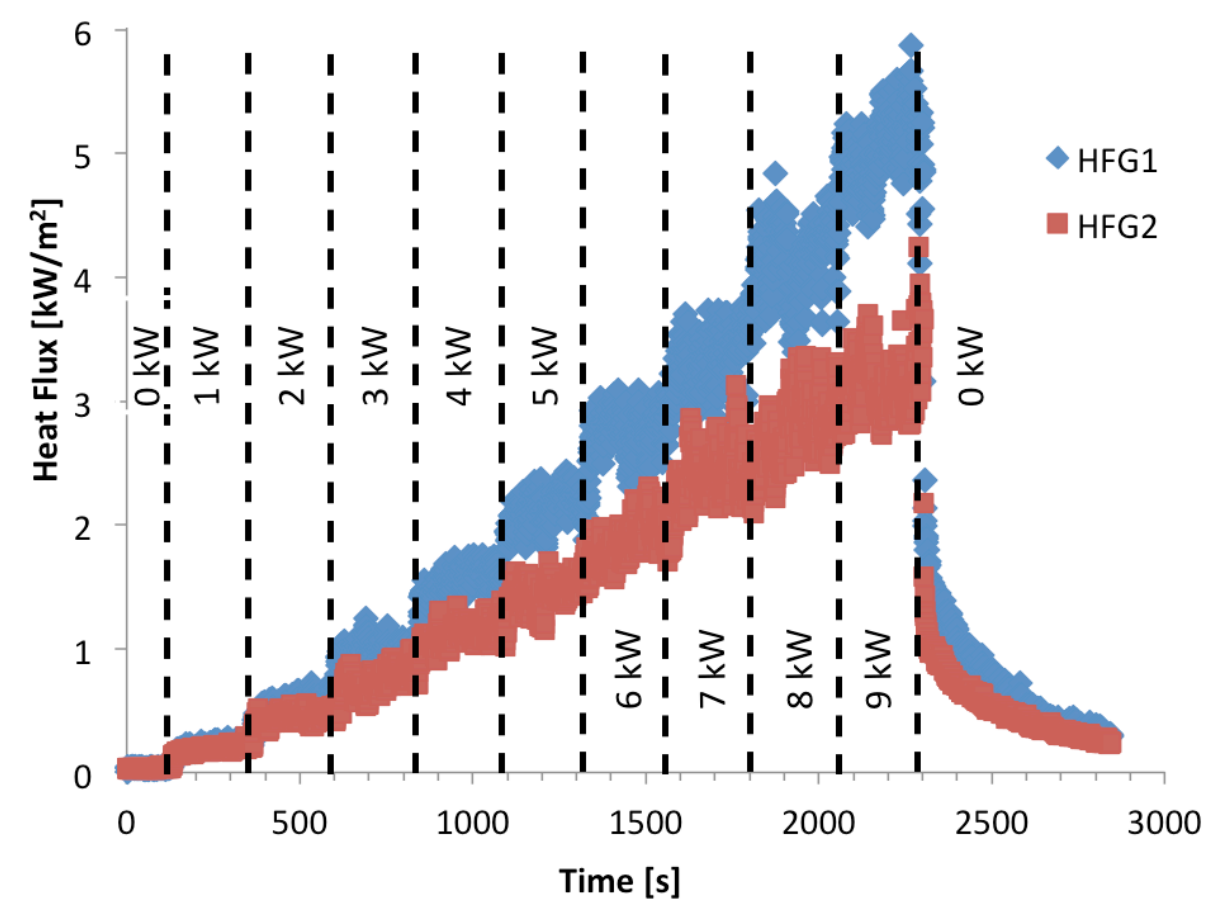

Figure 7. Raw data from test 2.2: the received heat flux $\left[\mathrm{kW} / \mathrm{m}^{2}\right]$ is plotted as a function of time $[\mathrm{s}]$. The vertical black dotted lines indicate the changes of the HRR over time. 
In order to study the distribution of the heat flux measurements as a function of the location, the measurements were averaged. To that purpose, the averaging was performed over 2 minutes per imposed HRR, once a new steady state had been obtained after increasing the HRR. These averaged values are then assumed to be constant, representative for that imposed HRR. If this heat flux exceeds the critical heat flux for the subjacent material, it is assumed to result in ignition and thereby a propagation of the fire.

The average received heat flux was calculated for all HRRs and all positions of the HFGs, making it possible to plot the measured heat flux as a function of the distance to the gas burner for test NP and WP, as seen from Figure 8. From subfigure A, which is test NP without the PV panel, it can be noticed that the measured heat flux is almost symmetrically distributed around the centre of the gas burner which is placed at a distance of $0 \mathrm{~cm}$. The measurements at the left side of the gas burner are slightly higher than the right side of the burner, though. This is probably due to a limited occasional draught towards the left side of the setup in the laboratory. The difference is small, but will be kept in mind for the conclusion. The measurements from test series B, with a PV panel installed in a geometry similar to commercial available mounting system, are shown in subfigure B. A significant increase of the heat flux is observed at all locations, when compared to the measurements without PV panel. As mentioned above, all the measurements underneath the most elevated part of the panel are higher than the measurements at the same distance from the burner underneath the least elevated part of the panel. This indicates the importance of the heat transfer by the flame, as mentioned above. This observation, along with the very fast decrease of the measured heat flux when switching off the burner (Figure 7, final period in the experiments) emphasises that the emission from the panel, compared to the heat transfer from the flame, is only a limited contributor to the total heat flux towards the subjacent surface.
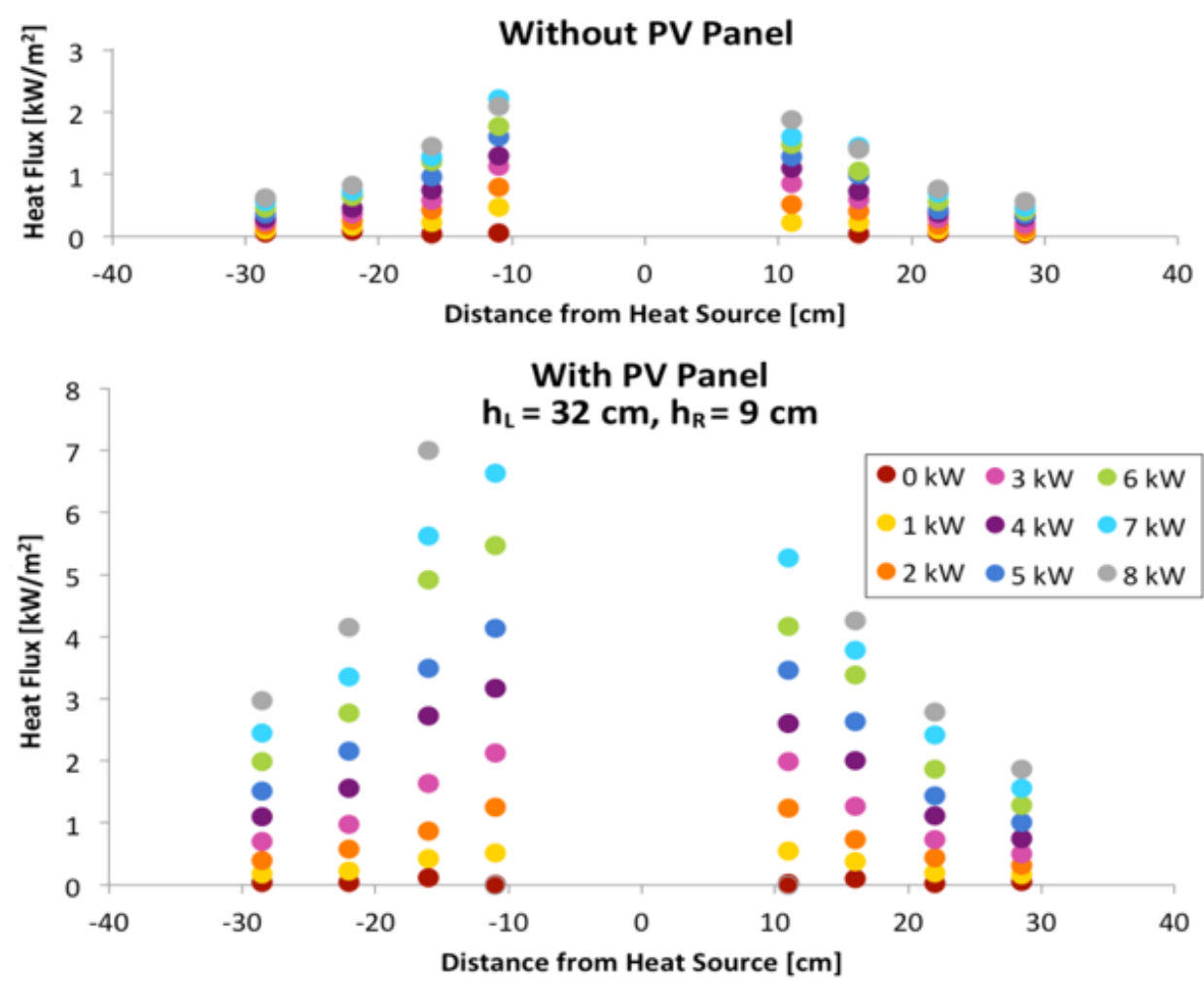

Figure 8. Averaged measured heat fluxes for test NP (top) and WP (bottom). The Heat Flux received as a function of distance to, and HRR from, the heat source. Each colored dot defines a HRR and the gas burner is placed at the distance of $0 \mathrm{~cm}$ from the heat source.

With the assumption that the amount of convective heat is limited due to the distance of the panel from the roof surface (Figure 6) and the fact that there is no accumulation of hot smoke, the differences between the measured heat fluxes at both sides of the gas burner are related to the radiation from the 
deflected flame from the gas burner. The influence of the flame can also be seen in Figure 9, where the percentage-wise increase of the received heat flux is plotted as a function of the HRR and the distance from the gas burner, as seen from Eqn. (1).

Where:

$$
I(D, \dot{Q})=\frac{\dot{q}^{\prime \prime}{ }_{W P}(D, \dot{Q})-\dot{q}^{\prime \prime}{ }_{N P}(D, \dot{Q})}{\dot{q}^{\prime \prime}{ }_{N P}(D, \dot{Q})} \times 100 \%
$$

$$
\begin{aligned}
& I(D, \dot{Q}): \quad \text { is the percentage-wise increase of the heat flux [\%] } \\
& D: \quad \text { is the distance from the gas burner }[\mathrm{cm}] \\
& \dot{Q}: \quad \text { is the HRR from the gas burner }[k W] \\
& \dot{q}^{\prime \prime}{ }_{W P}(D, \dot{Q}): \quad \begin{array}{l}
\text { heat flux received for a given distance and HRR in test with PV Panel } \\
{\left[\mathrm{kW} / \mathrm{m}^{2}\right]}
\end{array} \\
& \dot{q}^{\prime \prime}{ }_{N P}(D, \dot{Q}): \quad \begin{array}{l}
\text { heat flux received for a given distance and HRR in test with no PV panel } \\
{\left[\mathrm{kW} / \mathrm{m}^{2}\right]}
\end{array}
\end{aligned}
$$

A consistent observation for the plot is that the percentage-wise increase of the heat flux continues to grow for the three most distant positioned HFGs at the left side of the gas burner (i.e., underneath the most elevated part of the PV panel at distances of $-28.8 \mathrm{~cm},-22 \mathrm{~cm}$ and $-16 \mathrm{~cm}$ ), whereas the increase stabilises for the other positions (at values between $180 \%$ to $250 \%$ of the heat flux that would have been received without the panel). The continued growth, as a function of HRR, for the HFG positioned at the distances of $-16.0 \mathrm{~cm},-22.0 \mathrm{~cm}$ and $-28.5 \mathrm{~cm}$ probably occurs due to a HRR-related increase of the deflected flame length. The view factor for radiation from the flame increases significantly as the flame becomes longer, in particular when it reaches a position such that the heat flux meters were directly underneath the flame. Once this took place, the received heat flux hardly increased with further increase of the HRR from the burner, again confirming that the flame radiation was the dominant factor. This also explains why the heat fluxes at the right-hand side stabilised quickly and did not change significantly - the view factor from the flame hardly changed with an increased HRR from the burner. Only the emission from the panel increased, due to higher temperatures of the PV panel, caused by the higher HRR from the burner. Visual observations from the experiments supports this.

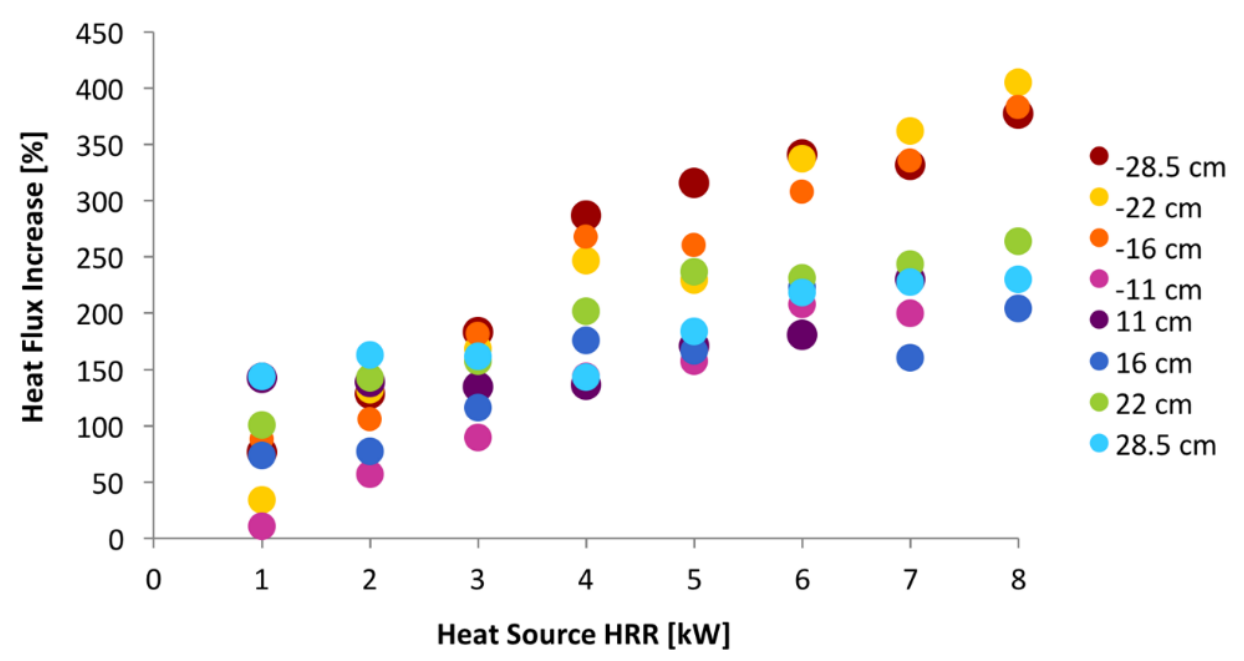

Figure 9. Overview of the percentage-wise increase of heat flux, as a function of the HRR from the gas burner, measured in the test without (NP) and with the PV panel (WP). 


\subsection{Reproducibility of tests}

The performance of the similar tests 2.4, with a reused panel, and 3.1, with a brand new panel (Table 1), made it possible to assess the effect of reusing panels in the experiments. Based on the raw data measurements it was not possible to verify the similarity using a 2-sample z-test with a $10 \%$ level of significance. Figure 10 therefore plots a 2-dimensional scatter diagram of paired data sets for the heat flux as received by the two heat flux gauges.

The diagram illustrates a good linear relation between the two tests, with two clearly deviating points, encircled in green, for the HRR of $4 \mathrm{~kW}$. This corresponds to a period where the combustible materials, such as the PV cell encapsulate and the back sheet of the PV panel, burn. Ignoring these 2 points, the slopes of the two trend lines indicate almost no difference between the heat flux underneath the new PV panel, compared to the panel tested for the fourth time. This confirms once again that the heat transfer from the flame is dominant.

However, during the burning period, the average heat fluxes measured underneath the brand-new PV panel was around $35 \%$ higher. Based on these observations, it can be concluded that the current measurements are representative for periods while the PV panels are not burning, and therefore are on the lower side of what can be expected during an actual fire (where the PV panels are by definition brand new with respect to fire). The increase occurred due to the combustion of the PV cell encapsulate and of the thin film on the backside of the PV panel, resulting in a short term growth of the heat flux.

Considering the low additional heat flux emitted due to the energy release from the panels, the main phenomenon responsible for the increased heat flux is the re-radiation from the deflected flame. Therefore, the findings of the paper may not only be relevant for PV panels, but to any inclined roof covering panel with limited combustibility (e.g. solar thermal panels).

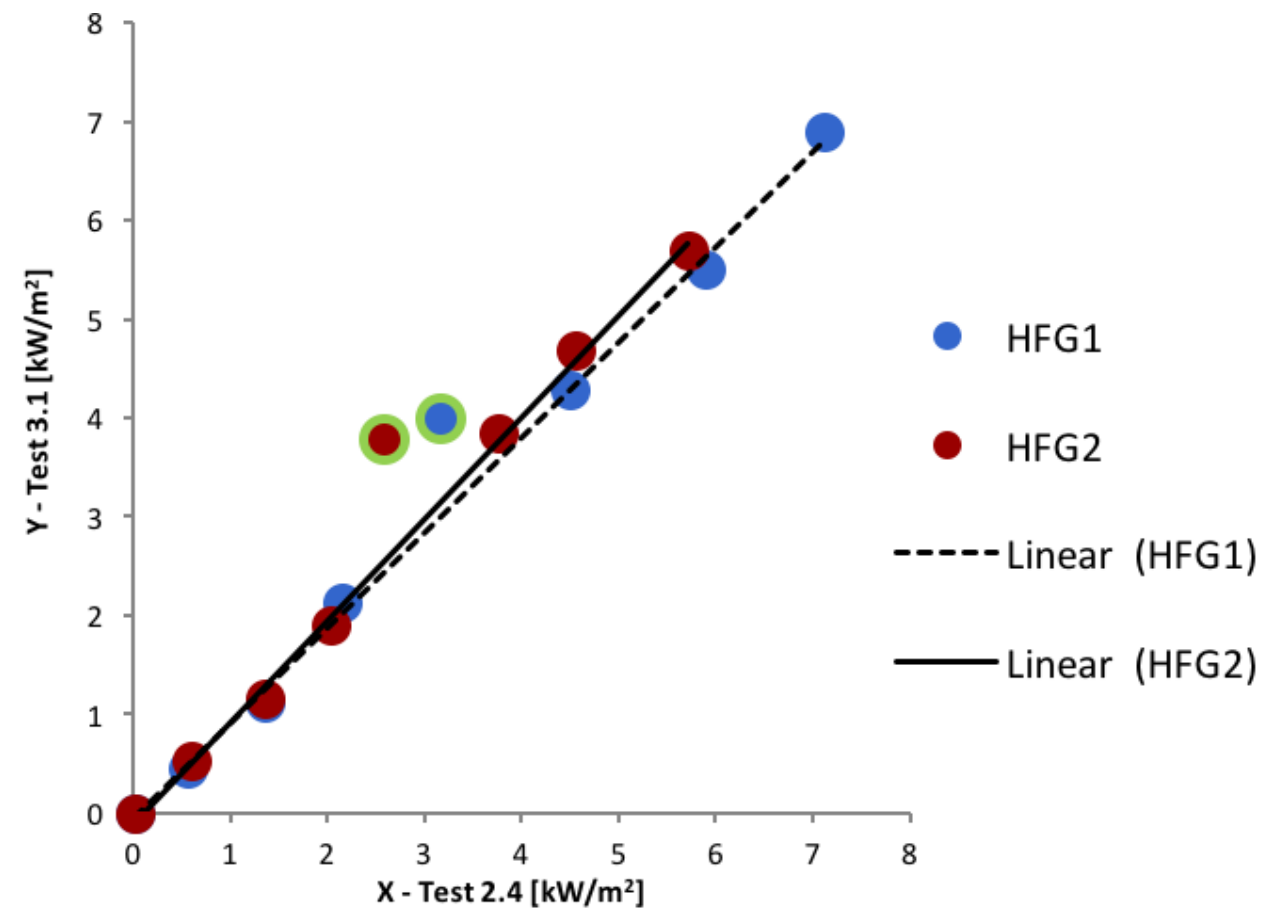

Figure 10. Two-dimensional scatter diagram of the paired data set from test 2.4 and 3.1, with and without the paired data for a HRR of $4 \mathrm{~kW}$. The two green lines encircle the two measurements made with a HRR of $4 \mathrm{~kW}$ and the two linear trend lines ignores these two measurements. 


\section{CONCLUSION}

Based on experiments where the received heat flux from a gas burner was measured at the nearby surface with and without the influence of a photovoltaic panel installed above the flame, it was seen that the installation of the PV array significantly increased the heat flux received on the subjacent surface. Based on view factor calculations alone, the highest incident radiative heat flux is expected underneath the least elevated part of the panel (because it is closer to the roof surface). However, for a fire source placed underneath the angled PV panel, the maximum incident heat flux was measured underneath the most elevated part of the panel, despite the lower value of the view factor (being further away from the roof surface). This illustrates that the heat flux from the flame, observed to deflect towards the most elevated part of the panel, is dominant in the incident heat flux, not the re-radiation from the PV panel.

PV panels can have a significant contribution in a fire hazard, as they stimulate fire spread over the roof on which they have been mounted. The current findings emphasise that the risk related to the installation of PV panels is not only associated with the increased fire load and possibility of ignition - but largely also with the changed fire dynamics on the roof construction. Furthermore, the fact that the heat flux from the combustible part of the PV panel represent an insignificant part of the total re-radiated heat flux indicates that the results is not only relevant for PV panels - but for all almost incombustible inclined panels installed on roof constructions.

Finally, the results could form the basis of a discussion regarding the level of fire related properties for roofing materials used underneath PV installations on flat roof constructions - as an improved reaction to fire performance of the roofing membranes could decrease the possibility of propagation underneath the arrays.

\section{ACKNOWLEDGEMENTS}

The authors would like to thank the Otto Mønsted Foundation, who funded Bart Merci as a visiting professor at the Technical University of Denmark. The PV panels used in the experiments were sponsored by IKEA Services AB as a part of a larger research project. The authors would furthermore like to thank research associate Bjørn Skjønning Andersen at the Technical University of Denmark, and Richard Clemenceau, laboratory intern from ISTIA - École d'igénieurs de l'Université d'Angers (France), for their assistance in the DTU Fire Laboratory. 


\section{REFERENCES}

1. Trends in Photovoltaic Applications Survey report of selected IEA countries between 1992 and 2006, IEA International Energy Agency, Report IEA_PVPS T1-16:2007, August 2007.

2. 2016 Snapshot of Global Photovoltaic Markets, IEA International Energy Agency, Report IEA PVPS T1-31:2017, 978-3-906042-589, 2017.

3. Solar Means Business 2015 Top U.S. Commercial Solar Users, SEIA Solar Energy Idustries Association, 202.862.0556, 2015.

4. P. Cancelliere, "PV electrical plants fire risk assessment and mitigation according to the Italian national fire services guidelines," Fire and Materials, p. 355-367, 5 December 2014

5. J. H. Wohlgemuth and S. R. Kurtz, "How Can We Make PV Modules Safer?," in IEEE Photovoltaic Specialists Conference, Austin, 2012.

6. A. Pandian, D. John Thiruvadigal and S. Sakthivel, "Fire Hazards and Overheating Caused by Shading Faults on Photo Voltaic Solar Panel," Fire Technology, vol. 52, p. 349-364, 6 June 2015.

7. B. Brooks, "The Ground-Fault Protection BLIND SPOT: A Safety Concern for Larfer Photovoltaic Systems in the United States.," [Online]. Available: http://solarabcs.org/about/publications/reports/blindspot/.

8. Y. Zhao, J-F de Palma, J. Mosesian, R. Lyons and B. Lehman, "Line-Line Fault Analysis and Protection Challenges n Solar Photovoltaic Arrays," IEEE TRANSACTIONS ON INDUSTRIAL ELECTRONICS, vol. 60, no. 9, 12 June 2012.

9. International Electrotechnical Commission - IEC, IEC 61730-2:2016, 2016.

10. Underwriters Laboratories Inc., UL 1703 Standard for Flat-Plate Photovoltaic Modules and Panels, Underwriters Laboratories Inc..

11. M.-C. Despinasse and S. Krueger, "First developments of a new test to evaluate the fire behavior of photovoltaic modules on roofs," Fire Safety Journal, vol. 71, pp. 49-57, 2015.

12. J. S. Kristensen, "Fire risk assessment of solar cell array installations on large buildings: How to protect the building in case of fire?," Lyngby, Denmark, 2015.

13. C. C. Grant, "Harnessing the Sun: Solar Power and Fire Protection Engineering," [Online]. Available: http://www.sfpe.org/?page=2014_Q3_4\&hh. [Accessed 111 2016].

14. R. Backstrom and D. A. Dini, "Firefighter Safety and Photovoltaic Installations Research Project," 2011.

15. C. C. Grant, "Fire Fighter Safety and Emergency Response for Solar Power Systems," The Fire Protection Research Foundation, Quincy, MA, 2010.

16. R. Tommasini, E. Pons, F. Palamara, C. Turturici and P. Colella, "Risk of electrocution during fire suppression activities involving photovoltaic systems," Fire Safety Journal, vol. 67, pp. 35-41, 2014.

17. L. Sherwood, B. Backstorm, D. Sloan, C. Flueckiger, B. Brooks and A. Rosenthal "Fire Classification Rating Testing of Stand-Off Mounted Photovoltaic Modules and Systems," Solar America Board for Codes and Standards Report, 2013.

18. Luca Fiorentini, L. Marmo, E. Danzi and V. Puccia, "Issue 99: Fires in Photovoltaic Systems: Lessons Learned from Fire Investigations in Italy", "SFPE emerging TRENDS enewsletter," 2015. [Online]. Available: http://www.sfpe.org/?page=FPE_ET_Issue_99\&hhSearchTerms=\%2299+and+fires\%22. [Accessed 19 October 2016 ].

19. Data behind Table 1 in "Issue 99: Fires in Photovoltaic Systems: Lessons Learned from Fire Investigations in Italy", Personal correspomdace with V. Puccia.

20. V. Babrauskas, Ignition Handbook, Issaquah: Fire Science Publishers, 2003, 2014, p. 28. 